\title{
Health Care for Elderly People in Rural Japan: Review of Issues and Analysis
}

\author{
Yoshiyuki Nagaya $^{1^{*}}$ and Albert Alipio ${ }^{2}$ \\ ${ }^{1}$ Kansai University of Social Welfare, Hyogo, Japan
}

${ }^{2}$ Australian Unity, Victoria, Australia

"Corresponding author: Yoshiyuki Nagaya, Assistant Professor, Registered Nurse (RN), Public Health Nurse (PHN), Master of Health Services Management and Planning (MHSM Plan), Kansai University of Social Welfare, 380-3, Shinden, Ako, Hyogo, 678-0255, Japan, Tel: +81(0)791-46-2525; Fax: +81(0)791-46-2526; E-mail: nagaya@kusw.ac.jp

Received date: November 09, 2017; Accepted date: December 12, 2017; Published date: December 20, 2017

Copyright: ( 2017 Nagaya Y, et al. This is an open-access article distributed under the terms of the Creative Commons Attribution License, which permits unrestricted use, distribution and reproduction in any medium, provided the original author and source are credited

\begin{abstract}
Various issues confront Japan's elderly population, particularly in rural areas. These issues need to be examined to fully understand the dynamics of the provision of health care. Only by understanding the different components and their impact on patient care can improvements be made to the delivery of services and ultimately the quality of care. In this review, a consideration of different aspects of care is undertaken, with a focus on rural areas. Potentials for improvements are also discussed. Electronic databases such as CiNii and ICHUSHI searched by Japanese and PubMed and CINAHL searched by English were searched to retrieve peer-reviewed primary research literature. A narrative synthesis of the findings sections of the papers was applied to identify key themes. These themes consider the range of issues affecting health care in rural Japan: Service delivery, distribution, resources, health care, rural and elderly. In total, eight papers with either qualitative or quantitative methodology were included in the review. The review highlights a broad range of issues being confronted, most of them likely to have a medium to long term impact on the quality of care in Japanese rural areas. Government, community and professional carers' attention to these issues is thus critical to ensuring improved health care to reassure a high quality of life for elderly in rural areas in Japan.
\end{abstract}

Keywords: Health care; Elderly; Distribution; Resources; Rural; Japan

\section{Introduction}

Japan's elderly population is continuing to grow. This means that the need or demand for health care services is forever increasing. Ensuring a high quality of care becomes a central task for health service provider/local and regional governments. A comprehensive understanding of the issues faced by the elderly in rural Japan is essential before strategies and reforms for the better delivery of care can be developed and implemented. The articles in this review emphasize challenges such as strained resources, inequity of distribution of resources, lack of support and dissatisfaction with care. Together these challenges highlight the need for effective strategies to tackle the issues confronting the elderly in rural Japan.

\section{Background}

Japan's population is one of world's most rapidly aging populations [1]. In 2014, Japan's total population was over 125 million [2], with close to 30 million people aged 65 or over (i.e., about $25 \%$ of the total population). Japan's elderly population is forecast to peak at a staggering 39 million in 2042. Also, Japan's population over the age of 75 years is expected to continue to rise [3]. The disproportionate growth in Japan's elderly population in comparison to the rest of its population will result in a growing demand for national medical and nursing care [4]. Considering Japan's rapidly aging population, the Japanese government has been encouraging and promoting a policy of comprehensive support and service delivery directed at health care for elderly people (Comprehensive Community Care System). The goal of the policy is to encourage elderly people to live independently, whilst maintaining a dignified lifestyle (Figure 1) [4].

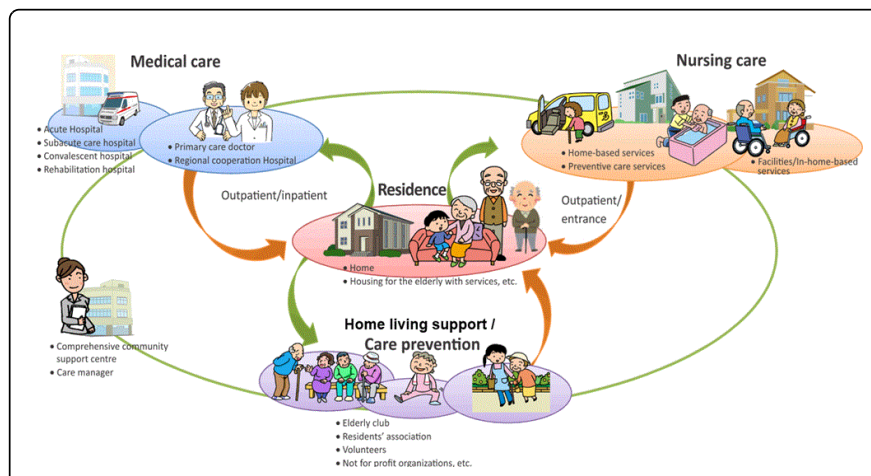

Figure 1: Comprehensive community care system.

One of the key aspects of the Japanese government's care policy for elderly people is for individuals to stay in their own homes, rather than move into nursing homes or specialized care facilities. Elderly persons who stay at home, however, are likely to require at least some support from professional services such as care, medical and/or preventative services. The Japanese government aims to develop initiatives that can operate together so as to provide life support and welfare services linked to an elderly person's home [5].

The key elements of the Japanese government's regional comprehensive care system are as follows: 


\section{Home}

An elderly person's home should be in good condition. In terms of safety and accessibility, for example, it might be difficult for elderly people to use stairs to move from floor to floor because of a decrease in lower limb muscle strength as they age. As a person's age increases, arrangements should be made to install hand rails in homes [6] that enable elderly persons to live safely. One's home is critical to an individual's life and is a source of not only abode but well-being. Also, the home provides an elderly person with dignity and protects their privacy.

\section{Home living support/welfare services}

Home living support is often provided to elderly people who have reduced cognition and physical capacity. Home living support provides elderly people with the opportunity to retain their family relationships, existing lifestyle and overall dignity. Home living support includes services such as meal preparation and informal assistance (e.g. neighborhood watch for local residents). Also, caregivers may be made available to help with daily life activities such as cooking, washing, cleaning, etc. Welfare services are provided to those elderly people who are not well-off financially; for example, those who rely on the government age pension as their sole or main means of support.

\section{Nursing/medical care/prevention}

Health professionals provide medical and health care and rehabilitation. Doctors, dentists, pharmacists and registered nurses visit the homes of elderly people regularly to monitor their health condition and physical therapists and occupational therapists provide elderly persons with rehabilitation if needed [7]. Care by health professionals can be integrated with home living support services in order maintain and monitor the health and living conditions of elderly individuals.

\section{Selection of elderly people/family and preparedness}

Culturally, Japanese families may not understand an elderly person's choice to live alone in their own home. It has become increasingly common for elderly persons to live alone, either as a single household or a household comprised of two or more elderly persons [8].

To improve the delivery of health care, each of the above elements should be monitored and managed by a comprehensive community support center or care manager [5]. Current Japanese government policy is to care for its elderly population. However, this policy is not in practice throughout Japan, particularly in rural areas where distance may impede communication between health professionals and elderly persons and limit accessibility to care.

\section{Search Methods}

Our study`s review involved a search of the databases CiNii and ICHUSHI searched in Japanese and CINAHL and PubMed in English. Also, hand-searching the reference lists of retrieved papers were conducted to recover primary research peer-reviewed literature in both English and Japanese published between January 1, 2007 and July 31, 2017. Table 1 detail the number of items initially retrieved, while Figure 2 highlights the screening process according to the Preferred Reporting Items for Systematic Reviews and Meta-Analyses guidelines [9]. Articles unrelated to the subject matter of the review were excluded on the basis that they were not relevant. In terms of exploratory inquiry, narrative reviews have the potential to make a valuable contribution to the literature. Due to the varied nature of the methods found in the studies retrieved, a narrative synthesis methodology [10] was considered appropriate. The search terms applied were: 'Health care' and 'elderly' and 'rural' and 'Japan'. The peer process was undertaken. Qualitative studies included in this review were appraised by applying the Critical Appraisal Skills Program qualitative research [11] and the non-experimental studies were assessed using Law's Critical Review Form [12]. The authors decided which papers should be included based on their relevance to the issues being examined. The findings sections of each paper were analyzed thematically and patterns were drawn across each study.

\begin{tabular}{|c|c|}
\hline Database & Records Retrieved \\
\hline $\mathrm{CiNii}$ & 93 \\
\hline ICHUSHI & 78 \\
\hline CINAHL & 5 \\
\hline PubMed & 181 \\
\hline $\begin{array}{l}\text { Hand serching from reference lists of } \\
\text { retrieveditems }\end{array}$ & 8 \\
\hline Total & 365 \\
\hline
\end{tabular}

Table 1: Records retrieved from sources.

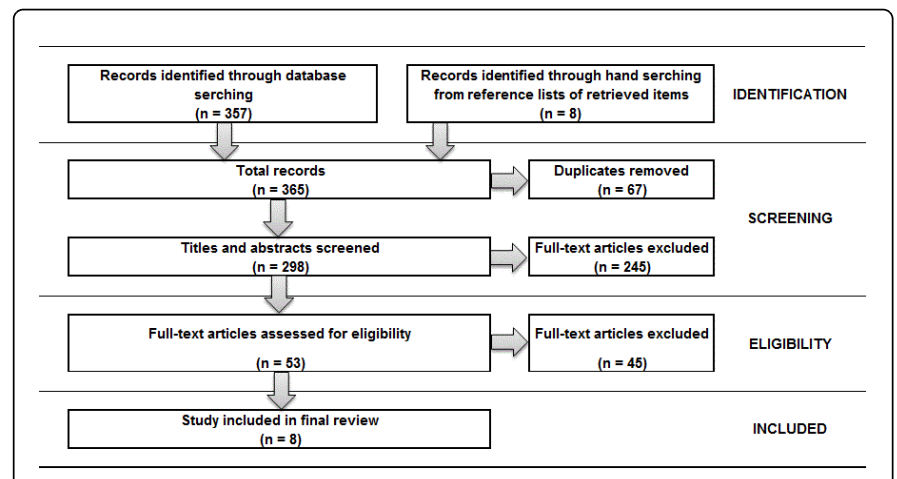

Figure 2: Preferred reporting diagram for systematic reviews and meta-analyses (PRISMA) showing selection for review.

\section{Results}

A summary of the studies included in the review is shown in Table 2. This research review included 8 papers. These papers described research conducted in rural areas of Japan. Six of the papers were qualitative studies, one paper was quantitative and one paper used mixed methods. Of the 8 papers, five did not identify the particular rural area studied in Japan. Three papers involved research on the main island of Japan's four islands. The findings for this project are presented according to the following key themes: The relation of stakeholders in the comprehensive community care system including medical care, nursing care and residence and home living support/care prevention. The issues confronting the delivery of health care for elderly people divided into three main factors: Personal views and concerns, different types of delivery and lack of resources (Figure 3). 


\begin{tabular}{|c|c|c|c|c|}
\hline References & Prefecture (Area of Japan) & Method/data gathering & Sample & Aim/objective/purpose \\
\hline Go et al. [13] & $\begin{array}{l}\text { Prefecture not specified } \\
\text { (mountainous area) }\end{array}$ & $\begin{array}{l}\text { Descriptive qualitative survey } \\
\text { design }\end{array}$ & $\begin{array}{l}14 \text { people in a town included elderly } \\
\text { support community organizations } \\
\text { representative, elderly support } \\
\text { groups and administrative staff in } \\
2007 .\end{array}$ & $\begin{array}{l}\text { To clarify the current status and } \\
\text { issues of elderly support network in } \\
\text { mountainous area }\end{array}$ \\
\hline Hamazaki et al. [14] & $\begin{array}{l}\text { Ishikawa (center of Honshu, } \\
\text { facing the Sea of Japan) }\end{array}$ & $\begin{array}{l}\text { Descriptive qualitative survey } \\
\text { design }\end{array}$ & $\begin{array}{l}259 \text { independent older people aged } \\
65 \text { years or older in the town in } 2010 \text {. }\end{array}$ & $\begin{array}{l}\text { To analyze the worries of } \\
\text { independent older people regarding } \\
\text { health and daily life }\end{array}$ \\
\hline Hara et al. [15] & Secondary medical areas & $\begin{array}{l}\text { The National Physician } \\
\text { Census, which is conducted } \\
\text { biannually by Japan's Ministry } \\
\text { of Health, Labour and Welfare } \\
(\mathrm{MHLW})\end{array}$ & $\begin{array}{l}349 \text { designated secondary medical } \\
\text { areas in } 2012 \text {. }\end{array}$ & $\begin{array}{l}\text { To examine geographic distribution } \\
\text { of Japanese doctors taking into } \\
\text { account age demographic of } \\
\text { population }\end{array}$ \\
\hline Kinugasa et al. [16] & $\begin{array}{l}\text { Tottori (coastal prefecture in } \\
\text { southern Honshu, Japan's main } \\
\text { island) }\end{array}$ & Quantitative survey & $\begin{array}{l}277 \text { consecutive patients } \\
\text { hospitalized in Tottori University } \\
\text { Hospital with a primary diagnosis of } \\
\text { heart failure from } 2006 \text { to } 2011 \text {. }\end{array}$ & $\begin{array}{l}\text { To examine whether intensive } \\
\text { inpatient education improves patient } \\
\text { outcomes in a rural setting }\end{array}$ \\
\hline Koyama et al. [17] & $\begin{array}{l}\text { Prefecture not specified } \\
\text { (depopulated rural area) }\end{array}$ & $\begin{array}{l}\text { Descriptive qualitative survey } \\
\text { design }\end{array}$ & $\begin{array}{l}6 \text { independent persons in daily life } \\
\text { aged } 75 \text { years or over in } 2008 .\end{array}$ & $\begin{array}{l}\text { To reveal the thought to the current } \\
\text { and future of life for independent } \\
\text { elderly }\end{array}$ \\
\hline Miyata et al. [18] & $\begin{array}{l}\text { Prefecture not specified } \\
\text { (Sparsely populated in mountain } \\
\text { villages) }\end{array}$ & $\begin{array}{l}\text { Descriptive qualitative survey } \\
\text { design }\end{array}$ & $\begin{array}{l}39 \text { families who had an elderly was } \\
\text { aged } 65 \text { years or over died from } \\
\text { January to December in } 2004 \text {. }\end{array}$ & $\begin{array}{l}\text { To examine the way of life support } \\
\text { through medical welfare services } \\
\text { elderly used in sparsely populated } \\
\text { mountain villages }\end{array}$ \\
\hline Urano et al. [19] & Gunma (central part of Honshu) & $\begin{array}{l}\text { Descriptive quantitative design } \\
\text { using validated instruments }\end{array}$ & $\begin{array}{l}\text { Suicide data which was separately } \\
\text { aggregation in Life-link suicide } \\
\text { statistics from } 2009 \text { to } 2012 \text { version } \\
\text { and A district from } 2008 \text { to } 2012 \text {. }\end{array}$ & $\begin{array}{l}\text { To clarify suicide rate rise factor in a } \\
\text { district }\end{array}$ \\
\hline $\begin{array}{l}\text { Yanagisawa et al. } \\
\text { [20] }\end{array}$ & Three rural towns & $\begin{array}{l}\text { An anonymous self- } \\
\text { administered questionnaire } \\
\text { and quantitative survey }\end{array}$ & $\begin{array}{l}364 \text { volunteers involved in cooking } \\
\text { and meal delivery services for elderly } \\
\text { in three rural towns in } 2005 \text {. }\end{array}$ & $\begin{array}{l}\text { To examine factors affecting patient } \\
\text { satisfaction with volunteers' work in a } \\
\text { meal delivery service for elderly }\end{array}$ \\
\hline
\end{tabular}

Table 2: Summary of studies included in the synthesis.

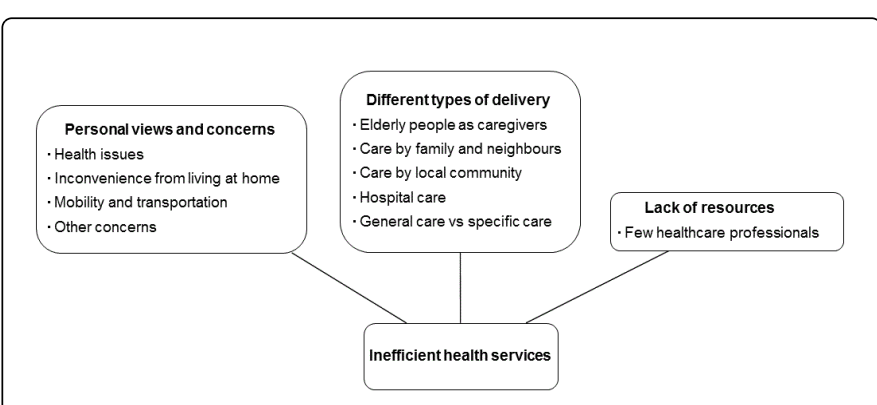

Figure 3: Issues confronting the delivery of health care for elderly people.

\section{Personal views and concerns}

Health issues: Physically, elderly people experience weakened mobility, deteriorating eyesight and impaired hearing. Also, elderly people often have to deal with chronic illness and related symptoms. Psychologically, they may suffer from dementia, an increased inability to control their emotions, reduced motivation and lack of sleep or insomnia related disease $[14,17,19]$. Elderly persons often report having negative feelings such as loneliness, isolation and depression.
Inconvenience from living at home: Another significant issue facing elderly people in rural Japan is the inconvenience of living at home as most of houses remain of the traditional Japanese style. As a person ages, they may find it increasingly difficult to undertake basic daily activities such as bathing, going up and down stairs and carrying out basic housework (e.g. cleaning, laundry, cooking and waste removal) [14,17].

Mobility and transportation: Elderly people also encounter difficulty outside of their homes. Their ability to move around is drastically reduced if they can no longer drive their own vehicles. Additionally, they may find it challenging to work out public transport routes or impossible to travel when there is limited or no available public transport. For example, in rural Japan, it is often difficult to find a supermarket within walking distance of an elderly person's home $[14,17]$.

Other concerns: Elderly persons also face multiple concerns. One concern is that they often worry about how to care for each other. Couples, for instance, tend to worry about each other. The elderly living alone tend to worry about not being able to contact someone in the event of an emergency. Another concern is that many elderly persons frequently find themselves in financial difficulty. Government support is increasingly limited and rising costs of living often leads to difficulty in meeting basic living costs $[14,17,19]$. The various 
difficulties affecting elderly people mean that different forms of care are likely to be required to ensure that the health of elderly persons can be maintained.

\section{Different types of delivery}

Elderly people as caregivers: Elderly people often report caring for each other due to the lack of available care in Japan. The involvement of elderly people in elderly care is fraught with difficulties. Care becomes more difficult when it is provided to those who are bedridden and/or experiencing loss of capacity (i.e., through dementia, etc.) [14]. While there are certainly benefits to having a number of individuals living together, rather than alone, this does not always guarantee that care will be available at all times. At times, the elderly people in a given household may experience simultaneously health issues that limit the extent of care that may be offered or rendering it non-existent. Care will eventually dissipate, as all the individuals reach a very advanced age [13].

Care by family and neighbors: The care of elderly people is frequently provided by younger family members and/or neighbors [13]. This often requires the elderly to stay at home and look after themselves for the majority most of the time. In fact, care from an elderly person's immediate family may only occur if the elderly person has been recently hospitalized. However, the need to rely on others for care, such as neighbors or volunteers often results in the feeling of having to reciprocate the care, a deeply rooted Japanese tradition. As such, Japanese individuals often feel the need to reciprocate kind actions (e.g. paying someone for their generosity). Unfortunately for the elderly, this notion may impose a financial or emotional burden that they may be incapable of carrying.

To prevent the need for reciprocation, elderly people may choose not to help a neighbor or friend. Alternately they may fear that they will be unable to assist and if they do help that they may hurt the other elderly person $[13,14,17]$. For example, an elderly person might not be physically strong enough to assist another elderly person wishing to move from one location to another. Moreover, Japanese customs pertaining to politeness often come into play. For instance, if someone visits a person's home, the host traditionally welcomes the guest by providing tea and snacks. However, since many elderly people have limited income, they may not be in a position to provide what is customary. These physical, social and economic constraints may affect their willingness to help others.

Another issue of concern is that at times elderly persons are relocated from their home by their own family without any consideration for the elderly person's view on the relocation. Conflicts may arise between an elderly person and their family when the elderly person lives alone. Elderly persons are often faced with the dilemma of choosing to live alone or feeling vulnerable because they have to be cared for by their family $[13,14,17,19]$.

Care by local community: Elderly persons can often feel isolated and lack interaction with their local communities. A person's engagement and involvement with their local community, gradually begins to lessen with age. This issue has been identified by Go et al. [13] as a serious problem in Japan. Go et al. [13] note that elderly individuals, particularly in rural Japan, have limited involvement with their local communities. In fact, many elderly people have been found to have limited social interaction with their neighbors.

Community interaction, however, can be beneficial for elderly persons. An elderly person's local community can offer care and support, much easier than anyone else. Community interaction may help raise the number of elderly persons living at home, rather than resorting to nursing home or hospital placement. Without community interaction, minimal support is obtained through community support systems. Community care and support, however, becomes increasingly difficult as a person's age advances past 75 [13]. Towards the end of an individual's life cycle, the demands for care can be expected to rise requiring more intensive assistance. The cost of providing $24 \mathrm{~h}$ care or more frequent visits by registered nurses, doctors or other professionals aimed at enabling elderly people to stay in their homes could become excessive.

Hospital care: Hospitals certainly play a critical role in providing health care to elderly persons. Studies have identified general dissatisfaction and negative views on the level of care (including nursing care) offered to elderly people in secondary hospitals and others offering end of life care [18]. Local hospitals often can act as an initial medical provider. However, in terms of end of life care, local hospitals have not been operating effectively. For example, the elderly often experience a sudden death event, shortly after being discharged from the local hospital. This has led to many families feeling great distress and dissatisfaction with local hospital care. Families feel that in order for care to improve, the hospital system will need to be more responsive to the needs of elderly people and their families. Otherwise, elderly persons and their families will increasingly avoid visiting hospitals and this could be detrimental to the general well-being and health of elderly people.

General care vs. specific care: For all of the different types of care provided to elderly people, it is generally acknowledged that specific care directed at the particular individual's circumstances is preferable to general care [13]. All elderly persons are unique and like the feeling of interacting with their family and possibly the broader community. Respecting the uniqueness of each individual is essential to the delivery of improved care.

\section{Lack of resources in rural areas}

Reduced supply of healthcare professionals: One of the significant issues facing the delivery of health care in rural areas is the falling ratio of health professionals to patients. Compared to rural areas, most physicians and other health professionals continue to be attracted to working in urban areas. When examining the delivery of health care, it is not simply the number of professionals providing care, but the demand for such care which must be taken into consideration [15].

\section{Ways to improve health care}

Education: The key to improving healthcare may be to implement initiatives that encourage education among health professionals, patients and others in the community delivering care. For instance, intensive multidisciplinary education has greatly improved management of inpatient heart failure. Multidisciplinary intensive education involves a combination of comprehensive team education, pre-discharge diagnostic tests and improved post-discharge outcomes [16].

Improved communication and relationships: To achieve improved health care requires improved communication and establishing relationships between patients and healthcare providers. For example, a study in Yanagisawa [20] examined the use of volunteers in the delivery of meal delivery services, proving it to be an effective strategy. Through improved communication and better relationships not only 
do the elderly feel better about the service they are receiving, but service providers will also feel motivated to work and develop closer relations with patients. This study also found that public health nurses can act as an effective intermediary between volunteers and patients. Given limited research, further research may prove beneficial to close the gap in literature.

\section{Discussion}

The issues confronting health care for elderly people in Japan could possibly be improved if the delivery of services was reorganized to encompass both urban and rural areas. This review of the literature points to several features of the health care system that could be improved upon. Building better relations between stakeholders such as care providers and the elderly requiring care could lead to efficient health delivery. In our review, we have identified 8 areas of importance:

\section{Family caregiving infrastructure}

Care is often provided by a range of individuals, including but not limited to extended family and paid caregivers. The general concept of care and support networks are widening beyond the traditional nuclear family model and including a broader range of professionals and nonprofessionals in the wider community [21]. On a positive note, rurally, by contrast to large metropolitan areas, the elderly tend to live with a family member who becomes their caregiver. This makes it easier to administer treatment in most cases [22].

\section{Day care centers}

Day care centers may work effectively in filling gaps in the provisions of health care. The elderly may need to use day care centers for physical care, social interaction or simply as a place to stay during the day when many family caregivers work. Some day care centers even offer rehabilitation services for elderly with dementia [23].

\section{Greater access to information}

Patients may be more prepared to accept certain types of care if they are first informed of the risks and effects of the care. A study on the use of vaccinations across Japan highlighted that when the availability of public information on the risks, severity of illness and efficacy of vaccinations is present, a greater willingness of patients was seen in accepting vaccinations [24].

\section{Type of home health nursing agencies}

Care provided by home health nursing agencies is most effective when there are caregivers present. That is, after daily duties have been fulfilled by family or home assistance services, care may be supplemented by nursing agencies. Access to agencies has been found to improve the overall delivery of health care. However, affordability of access to agencies is often an issue for low income earners who have high-care needs. Equitable access to home health services across income earners is important to ensure improved the elderly outcomes [25].

\section{Availability of physicians}

A study by Sasaki, Otsubo and Imanaka in 2013 found that the numbers of physicians may be driven by a lack of incentives attracting physicians to rural areas which leads to their concentration in metropolitan areas. This is particularly the case for women and physicians under age 40.To encourage more doctors to rural areas, the study authors suggest a change in policy is needed from legal and financial incentives to measures promoting opportunities for better work-life balance in rural areas [26].

\section{Relationship between regional health expenditure and health}

High patient satisfaction is not always reflected in improved morbidity and mortality. Satisfaction and quality of care are not necessarily correlated. Care needs to be evidence based and patientcentered rather than emphasizing solely on patient satisfaction. An over focus on patient satisfaction, therefore, could potentially have a negative effect on health care utilization, expenditure and outcomes [27].

A common consensus is that lower health care spending worsens the general state of health care delivery. However, significant health care spending does not always equate to better health outcomes. Healthcare outcomes are often achieved when medium spending is undertaken on health care. A solution may be to focus on median spending as an optimal choice that allows for money-saving without completely compromising patient outcomes [28]. Unfortunately, the Japanese government's reform agenda still tends to focus on reducing administrative and financial costs (to improve economic efficiency) that proves detrimental to overall patient care.

\section{Patients' rights}

One of the roles of government should be to implement reforms emphasizing patients' rights. An emphasis on patients may bring about an integration of public health, health care and nursing care [28]. Currently there are no effective mechanisms for government to consider patients views about the health services they receive.

\section{Volunteer work performance measures}

Volunteers providing health care services should be reviewed for their performance. Performance review structures would help volunteers obtain valuable feedback. In addition, they would offer support and recognition which will continue to motivate volunteerism [29].

\section{International comparison}

Outside of Japan, international studies have described implementation of initiatives affecting an effective system of health care for elderly people in rural areas. The experience overseas allows for useful comparison in Japan. Positive initiatives developed and implemented overseas may also provide insight for application in Japan. The Japanese government should therefore evaluate and implement some of the measures used and successful overseas.

For example, Germany like Japan faces a rapidly aging population. Germany has also noted deteriorating health care service delivery in rural areas, particularly, the shortage of health care professionals in these areas. To address this, Germany has now introduced initiatives designed to attract medical students to regional areas. Incentives, in the form of financial support are offered to those medical students who commit themselves to practicing the first years after obtaining their degree in a region with a shortage of supply of health professionals [30]. In Thuringia, young medical practitioners who qualify as specialists or as general practitioners are supported financially if they 
work in rural areas [31]. It is hoped that these financial measures will contribute to better health care outcomes in rural areas of Germany. Given the success of these initiatives, the Japanese government should consider offering similar financial support to health professionals who choose to practice in rural areas. These types of initiatives could subsequently help to contribute to improvements in hospital care in rural areas of Japan. These initiatives would help to improve hospital care in rural Japan and change negative perceptions from elderly people and their families.

Technology has also been used to address difficulties in health care in Europe. In Germany, technology use among healthcare providers has proved to be an effective means for the improvement of the delivery of health care $[32,33]$. Additionally, Italy, Greece and Cyprus have started using an integrated broadband communication platform to care for elderly persons dispersed in remote areas.

The technology uses various forms of communication infrastructures designed to allow communication between persons in need of care and health professionals. The technology has proved useful in connecting health professionals with elderly people. Even broader use of the technology is therefore likely to be on the policy agenda in Mediterranean Europe. The use of telemedicine and teleconsultation may result in lower costs by limiting medical transfers to a minimum, reducing morbidity and mortality of patients and improved quality of life as a result of higher quality health care [34].

Just as in other countries, it would seem that in Japan, technology is likely to play a critical role in the future delivery of health care to elderly people in rural areas. Technology may improve communication flows between elderly persons themselves, between elderly people and their health professionals and between health professionals in different regions of Japan. The interaction of technology with community health care, in Japan, therefore, may offer significant benefits to health care.

In Canada, research has found that successful elderly people health care in rural areas extends beyond access to doctors and/or traditional health care. Housing, care giving and transportation, in particular, play a crucial role in ensuring the health of Canada's elderly population. Canada's research supports the need for a broader range of health services to address the quality of life of elderly people, including the provision of home care and respite care services. Many elderly Canadians are forced to move out of their former communities due to limited housing options, a lack of formal transportation services, growing financial concerns and inadequate caregiver support. Research in Canada lends support to a broader approach to addressing seniors' health care needs than the traditional care model. Increasing numbers of elderly people in rural areas of Canada call for greater attention to healthy aging [35]. Research in Canada is consistent with research in Japan. Both support a move beyond traditional health care models in order to address the difficulties of care in rural areas. As with Canada, the Japanese government has begun to recognize the importance of additional factors such as housing for elderly people, care giving and transportation in delivering effective health care.

Studies conducted by Allan, Bal and Alston [36] in Australia suggest that the focus of health care should firstly be to identify needs more effectively. This requires consistent and concerted efforts to collect community information in a systematic way. If all healthcare providers are involved in profiling the health and welfare needs of the population, needs can be properly identified and developed to create effective strategies [36]. Japan is only now beginning to consider the specific needs of each elderly individual. With a continued focus on individualized needs, health care in rural Japan should improve. Using Australia's platform, greater profiling of elderly individuals may assist in the future delivery of improved health care in Japan.

\section{Conclusion}

Around the world, health care for elderly people, particularly in rural areas, is a complex issue. However, it is an issue increasingly facing many countries as the growth of their elderly population outpaces other population growth. Traditional health care alone has proven ineffective in ensuring that the quality of life of elderly persons is maintained. Other aspects of care, addressing housing and transportation, disparity of resources, patient dissatisfaction and financial support also need to consider. Comprehensive and innovative policy solutions are necessary to ensure elderly people in rural areas remain healthy while aging. Additionally, educational programs, availability of healthcare information and improved service delivery are likely to prove critical in rural Japan. At present, Japan's focus on preventative measures, helps alleviate the need for physical nursing care. An approach combining different forms of care is preferable. The approach needs to be wide-ranging factoring psychological, socioeconomic, environmental, safety, financial and societal elements into the health care equation. The key is to ensure that elderly people can live independently without been forgotten, which is often the case in rural Japan.

A broader model of health care encompassing a more comprehensive approach to care is also developing globally. A focus on specific needs is common among those countries implementing innovative methods of care. Ultimately, however, many of the measures taken in addressing elderly people health care will be impacted by the extent of resources directed to the health care system. Attracting health professionals to rural areas through financial incentives, for instance, are bound to prove vital. In many respects, the experience worldwide is similar. Japan thus stands to benefit not only from expanding and broadening its own knowledge base, but also from the experience and innovative measures taken overseas.

A continued generalist approach to health care is unlikely to succeed. Therefore, individualized health care needs to be more specific, catering to the needs of the individual. Access to health care means access to hospitals and quality professional care which is usually limited in rural areas, denying many choices for elderly people in health care. Elderly people need to be taught to care for themselves to a certain extent. Mutual support and care, between elderly people, health professionals, volunteers and youth in local communities can greatly increase the level of care in communities, without drawing significantly on resources. Finally, as the experience in other countries is demonstrating, technology and access to effective and efficient communication networks may also prove key in assisting with ongoing improvements in health care across Japan.

\section{References}

1. World Population Ageing (2013) NY, United States of America.

2. Ministry of Internal Affairs and Communications Statistics (2015) Population projections. Tokyo, Japan.

3. National Institute of Population and Social Security Research (2012) Future estimated population of Japan. Tokyo, Japan.

4. Ministry of Health, Labor and Welfare (2014) Long-term estimates in the medical and nursing care. Tokyo, Japan. 
5. Ministry of Health, Labor and Welfare (2013) Regional Comprehensive Care Study Group. Tokyo, Japan.

6. Long-Term Care Insurance Act of 1997 (2015a).

7. Long-Term Care Insurance Act of 1997 (2015b).

8. Kanayama $\mathrm{T}$ (2003) Ethnographic research on the experience of Japanese elderly people online. New Media Society 5: 267-288.

9. Moher D, Liberati A, Tetzlaff J, Altman D (2009) Preferred reporting items for systematic reviews and meta-analyses: The PRISMA statement. Ann Intern Med 151: 264-269.

10. Popay J, Roberts H, Sowden A, Petticrew M, Arai L, et al. (2006) Guidance on the conduct of narrative synthesis in systematic reviews: A product from the ESRC methods programme, Institute of Health Research, Lancaster, United Kingdom.

11. Public Health Resource Unit (2006) The critical skills appraisal programme: Making sense of evidence, Oxford, United Kingdom.

12. Law M, Stewart D, Letts L, Pollock N, Bosch J, et al. (1998) Guidelines for critical review form: Qualitative studies. McMaster University Occupational Therapy Evidence-Based Practice Research Group, Ontario, Canada.

13. Go Y, Muramatsu T, Sasuga Y, Koyama T, Kohno Y, et al. (2009) Current situation and issues of elderly support network in an underpopulated mountain region: Analysis of a work shop for elderly support groups in A-town. Yamanashi Prefectural University 11: 1-11.

14. Hamazaki Y, Nagai M (2012) Worries of independent older people regarding health and daily life: A survey of residents of a rural town in Japan. J Community Health Nurs 29: 225-235.

15. Hara K, Otsubo T, Kunisawa S, Imanaka Y (2016) Examining sufficiency and equity in the geographic distribution of physicians in Japan: A longitudinal study. BMJ Open 7: e013922.

16. Kinugasa Y, Kato M, Sugihara S, Yanagihara K, Yamada K, et al. (2014) Multidisciplinary intensive education in the hospital improves outcomes for hospitalized heart failure patients in a Japanese rural setting. BMC Health Serv Res 14: 351.

17. Koyama T, Sasuga Y, Kohno Y, Muramatsu T, Go Y, et al. (2009) The thoughts toward present and future life: The thoughts of person aged 75 or over living alone in the depopulation farming and mountain district. Yamanashi Prefectural University 11: 27-37.

18. Miyata N, Yasue E, Hashimoto H, Shimoi K, Kamihira K, et al. (2007) Nursing attendances by elderly persons family and medical welfare services in a depopulated area. Gifu University of Medical Science 1: 131-140.

19. Urano K, Yamamoto A, Yamada Y, Sugiki Y, Koike M, et al. (2014) Factors contributing to a high rate of suicides in a local health and medical district in Gunma prefecture with an aging and declining population. Kitakanto Medical Journal 64: 325-333.

20. Yanagisawa $H$, Sakakibara $H(2008)$ Factors affecting satisfaction levels of Japanese volunteers in meal delivery services for the elderly. Public Health Nurs 25: 471-479.
21. Murray M (2008) The networked family: Reframing the legal understanding of caregiving and caregivers. Virginia Law Review 94: 385-454.

22. Shinagawa S, Yatabe Y, Hashimoto M, Nakayama K, Ikeda M (2012) A comparison of family care infrastructure for demented elderly in inner cities and regional areas in Japan. Psychogeriatrics 395: 159-164.

23. Nishino $\mathrm{T}$ (2011) A case study on roles and systems of day care centers for the elderly, from the point of users' types in a middle mountainous area. Journal of Architecture and Planning 76: 19-26.

24. Matsui D, Shigeta M, Ozasa K, Kuriyama N, Watanabe I, et al. (2011) Factors associated with influenza vaccination status of residents of a rural community in Japan. BMC Public Health 11: 149.

25. Kashiwagi M, Tamiya N, Sato M, Yano E (2013) Factors associated with the use of home-visit nursing services covered by the long-term care insurance in rural Japan: A cross-sectional study. BMC Geriatr 13: 1.

26. Sasaki H, Otsubo T, Imanaka Y (2013) Widening disparity in the geographic distribution of pediatricians in Japan. Hum Resour Health 11: 59.

27. Fenton J, Jerant A, Bertakis K, Franks P (2012) A national study of patient satisfaction, health care utilization, expenditures and mortality. Arch Intern Med 172: 405-411.

28. Tsugawa Y, Hasegawa K, Hiraide A, Jha, A (2015) Regional health expenditure and health outcomes after out-of-hospital cardiac arrest in Japan: An observational study. BMJ Open 5: e008374.

29. Millette V, Gagne M (2008) Designing volunteers' tasks to maximize motivation, satisfaction and performance: The impact of job characteristics on volunteer engagement. Motiv Emot 32: 11-22.

30. Kassenärztliche Vereinigung Sachsen-Anhalt (2010) Scholarship program for medical students: Getting scholarships. Magdeburg, Germany.

31. Foundation for the Promotion of outpatient medical care in the Free State of Thuringia (2010).

32. Lamminen J, Forsvik H, Vopio V, Ruohonen K (2011) Teleconsultation: Changes in technology and costs over a 12 year period. J Telemed Telecare 17: 412-416.

33. Olenik K, Lehr B (2013) Counteracting brain drain of health professionals from rural areas via teleconsultation: Analysis of the barriers and success factors of teleconsultation. J Public Health 21: 357-364.

34. Mougiakakou S, Kyriacou E, Perakis K, Papadopoulos H, Androulidakis A, et al. (2011) A feasibility study for the provision of electronic healthcare tools and services in areas of Greece, Cyprus and Italy. Biomed Eng Online 10: 49 .

35. Bacsu J, Jeffery B, Johnson S, Martz D, Novik N, et al. (2012) Healthy aging in place: Supporting rural seniors' health needs. Online Journal of Rural Nursing and Health Care 12: 77-87.

36. Allan J, Ball P, Alston M (2007) Developing sustainable models of rural health care: A community development approach. Rural and Remote Health 7: 818 . 